\title{
Natural resolution of a herniated lumbar disc
}

\author{
Douglas G Chang, ${ }^{1}$ Stephen Shymon, ${ }^{2}$ Aaron J Powell ${ }^{3}$
}

${ }^{1}$ Department of Orthopaedic Surgery, UC San Diego, San Diego, California, USA

${ }^{2}$ School of Medicine, UC San Diego, San Diego, California, USA

${ }^{3}$ Department of Physical Medicine and Rehabilitation, UC Davis, Sacramento, California, USA

Correspondence to Dr Douglas G Chang, dchang@ucsd.edu

\section{DESCRIPTION}

A middle-aged patient with a history of mild, intermittent low back pain presented with several months of new right leg pain and numbness in the L5 dermatomal distribution. The pain had not improved with trials of physical therapy, gabapentin or tramadol. The patient denied weakness or bowel and bladder symptoms.

Physical examination was significant for reproduction of leg symptoms with spine flexion and straight leg raise. Palpation of the right lumbar paraspinal musculature produced mild discomfort and myofascial spasm. Strength, sensation and reflexes were normal in the bilateral lower extremities. MRI at $1.5 \mathrm{~T}$ of the lumbar spine revealed a large L4-L5 disc extrusion producing severe central canal stenosis and mild-to-moderate bilateral neuroforaminal narrowing (figure 1). Near complete resolution of symptoms was achieved with a subsequent steroid injection of $80 \mathrm{mg}$ triamcinolone acetonide in $2.5 \mathrm{~mL}$ lidocaine $1 \%$ and $10 \mathrm{~mL}$ normal saline. Repeat MRI of the lumbar spine 20 months later demonstrated resolution of the disc extrusion (figure 2). The patient continued to have mild intermittent symptoms, but largely remained pain free.
MRI of the spine is the modality of choice when evaluating disc pathologies. ${ }^{1}$ However, clinical correlation with back pain can be difficult as up to $76 \%$ of asymptomatic individuals may have MRI evidence of disc herniation. ${ }^{2}$ Differentiating between disc protrusion and extrusion on MRI may improve specificity in identification of clinically important disc pathologies. ${ }^{3}$ Regardless, the finding that correlates most with clinical symptoms is the encroachment or compromise of neural elements by disc material, such as the exiting nerve root, which occurs in lumbosacral radiculopathy or sciatica. ${ }^{2}$ Sciatica is a very common condition affecting $13-40 \%$ of people during their life. ${ }^{4}$ The natural history of leg pain secondary to radiculopathy is favourable, with most patients improving within months of the injury without surgery. ${ }^{5}$ Because of this, non-operative treatments including epidural steroid injections should be considered before progressing to surgery. ${ }^{6}$ Finally, often CT or MRI will demonstrate spontaneous resolution of disc herniation, as it did in our case, though few studies have captured this at such high resolution. While it is common practice to reimage patients with persistent sciatica symptoms, caution should be taken as the clinical utility and correlation of these images is currently under debate. ${ }^{7}$

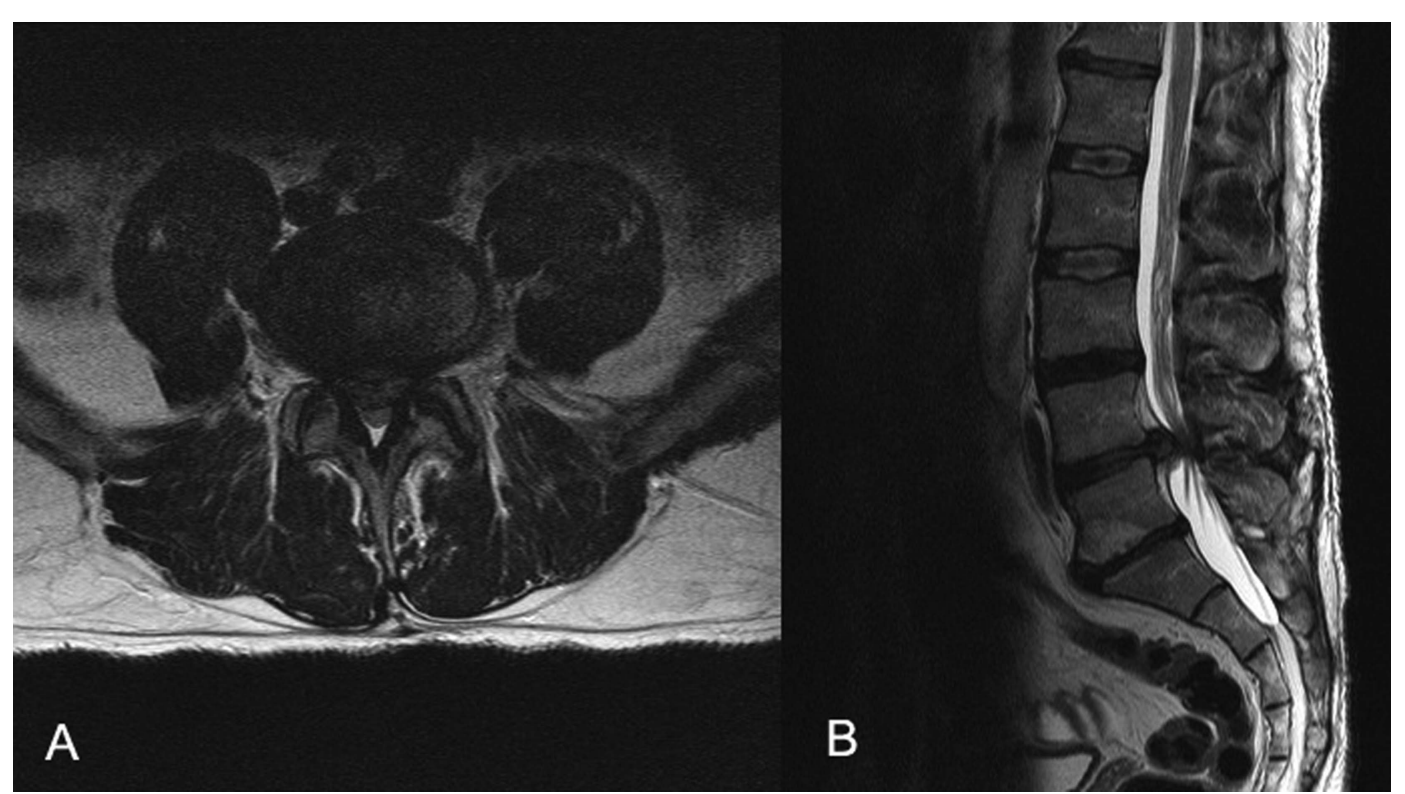

Figure $1 \mathrm{MRI}$ of the lumbar spine with T2 sequencing demonstrating a large disc extrusion resulting in severe central canal stenosis and bilateral neuroforaminal narrowing at $\mathrm{L} 4-\mathrm{L} 5$ in axial (A) as well as sagittal (B) planes. 
Figure $2 \mathrm{MRI}$ of the lumbar spine with $\mathrm{T} 2$ sequencing, 20 months after prior imaging, demonstrating resolution of $\mathrm{L} 4-\mathrm{L} 5$ intervertebral disc extrusion with resulting near resolution of central canal stenosis in axial (C) as well as sagittal (D) planes.

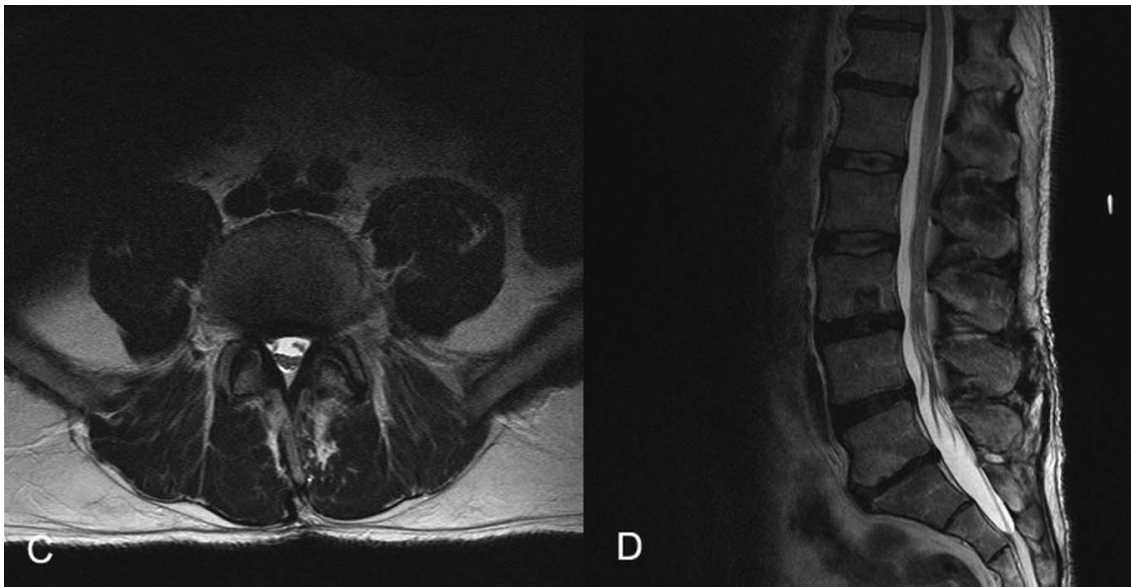

\section{Learning points}

- A intervertebral disc herniation will usually improve spontaneously over a period of months.

- A majority of patients with sciatica type leg symptoms secondary to disc herniation will improve with conservative treatment and not require surgery.

- Epidural steroid injections can be helpful in this patient population for resolution of the sciatica type radicular symptoms.

- Resolution of the disc herniation on MRI may not correlate with symptomatic improvement clinically.

Contributors DC was involved in conception and design, acquisition of data, literature review and critical revision of the manuscript and submission. He is responsible as the overall content guarantor. SS was involved in acquisition, compilation and interpretation of the initial data, communication and drafting the manuscript. AP was involved in analysis and interpretation of the data, secondary literature review, drafting and critical revision of the manuscript for important intellectual content.
Competing interests None.

Provenance and peer review Not commissioned; externally peer reviewed

\section{REFERENCES}

1 Wassenaar M, Van Rijn RM, Van Tulder MW, et al. Magnetic resonance imaging for diagnosing lumbar spinal pathology in adult patients with low back pain or sciatica: a diagnostic systematic review. Eur Spine J Off Publ Eur Spine Soc Eur Spinal Deform Soc Eur Sect Cerv Spine Res Soc 2012;21:220-7.

2 Boos N, Rieder R, Schade V, et al. 1995 Volvo Award in clinical sciences. The diagnostic accuracy of magnetic resonance imaging, work perception, and psychosocial factors in identifying symptomatic disc herniations. Spine 1995;20:2613-25.

3 Jensen MC, Brant-Zawadzki MN, Obuchowski N, et al. Magnetic resonance imaging of the lumbar spine in people without back pain. N Engl J Med 1994;331:69-73.

4 Stafford MA, Peng P, Hill DA. Sciatica: a review of history, epidemiology, pathogenesis, and the role of epidural steroid injection in management. $\mathrm{Br} J$ Anaesth 2007:99:461-73.

5 Bush K, Cowan N, Katz DE, et al. The natural history of sciatica associated with disc pathology. A prospective study with clinical and independent radiologic follow-up. Spine 1992;17:1205-12.

6 Riew KD, Yin Y, Gilula $L$, et al. The effect of nerve-root injections on the need for operative treatment of lumbar radicular pain. A prospective, randomized, controlled, double-blind study. J Bone Joint Surg Am 2000;82-A:1589-93.

7 El Barzouhi A, Vleggeert-Lankamp CLAM, Lycklama à Nijeholt GJ, et al. Magnetic resonance imaging in follow-up assessment of sciatica. $N$ Engl J Med 2013;368:999-1007

Copyright 2013 BMJ Publishing Group. All rights reserved. For permission to reuse any of this content visit

http://group.bmj.com/group/rights-licensing/permissions.

BMJ Case Report Fellows may re-use this article for personal use and teaching without any further permission.

Become a Fellow of BMJ Case Reports today and you can

- Submit as many cases as you like

- Enjoy fast sympathetic peer review and rapid publication of accepted articles

- Access all the published articles

- Re-use any of the published material for personal use and teaching without further permission

For information on Institutional Fellowships contact consortiasales@bmjgroup.com

Visit casereports.bmj.com for more articles like this and to become a Fellow 